\title{
Effect on the parameters of the high-heel shoe and transfer time of ground reaction force during level walking
}

\author{
Seung-Hyun Hyun, Young-Pyo Kim, Che-Cheong Ryew* \\ Department of Kinesiology, College of Natural Science, Jeju National University, Jeju, Korea
}

This study aimed to analyze an effect on the parameters of high-heel shoe and transfer time of ground reaction force during level walking and subjects participated were composed of adult female subjects ( $n=13$ ) of 20 s with height of high heel $(0 \mathrm{~cm}, 9 \mathrm{~cm}$, respectively). Instrument used for the study was 1 set force plate (AMTI-OR9-7) and sampling rate for data collection of analysis parameters was set-up at 1,000 $\mathrm{Hz}$. The revelation of required coefficient of friction (RCOF) maximum showed significant difference with more rapid than that of 1st peak vertical force (1 PVF). Transfer time of body weight showed significant difference with more delay at $9 \mathrm{~cm}$ than that of $0 \mathrm{~cm}$. RCOF required more frictional force required because PVF showed significant difference with larger value on $9 \mathrm{~cm}$ than that of $3 \mathrm{~cm}$ at 1 PVF. Both center of pressure (COP) $x$ and COPy showed rather less displacement on $9 \mathrm{~cm}$ than that of $0 \mathrm{~cm}$. In addition, level walking by high heel shoe did not control efficiently the ground reaction force due to restricted control capacity of coefficient of frictional force and therefore could suggest an inducement of muscle fatigue, heightening a possibility of sliding and falling due to decrease of frictional force.

Keywords: High-heel shoes, Walking, Required coefficient of friction, Ground reaction force, Torque

\section{INTRODUCTION}

Center of mass (COM) was accelerated forwardly by three-dimensional external force during bipedal walking. Then the foot overloaded by body weight primarily absorbs and transfers ground reaction force (GRF) to whole body.

Foot segment structured with complex and rigid anatomical skeleton (Leardini et al., 1999) keep up the function of flexibility, stiffness and stability etc. (Rodgers, 1995). The above functions can absorb and counteract biomechanical disparity within proper range during locomotion (Gerber et al., 2012), but reduce their functions in case of over-work range (Csapo et al., 2010). For the above reasons, function of shoe wearing must be satisfied to protect and utilize effectively of inherent function of foot during lo- comotion and other activities, and then can provide each user with static and dynamic stability (Nigg et al., 2006).

But high-heel shoe wearing frequently by young female among various types of shoes cause injurious side-effects and show tendency of more plantar flection effect than that of bare-walking on sagittal plane (Hyun and Ryew, 2014a) due to instability in anterior-posterior direction with increase of moment of inertia of body relatively (Ryu, 2010).

Walking cycle can be divided into braking, supporting and propulsive phase, of which braking phase can be defined as phase of initial touch of heel to ground, then the higher heel, the more vertical reaction force and breaking force linearly (Stefanyshyn et al., 2000). Impact force can cause amplitude wave of high impact and transfer to the other joint of body through various muscu-

\footnotetext{
${ }^{*}$ Corresponding author: Che-Cheong Ryew (D) http://orcid.org/0000-0001-9473-3990 Department of Kinesiology, College of Natural Science, Jeju National University, 102, Jejudaehak-ro, Jeju 63243, Korea

Tel: +82-64-754-3588, Fax: +82-64-757-1752, E-mail: ryew@jejunu.ac.kr

Received: March 3, 2016 / Accepted: September 5, 2016
}

This is an Open Access article distributed under the terms of the Creative Commons Attribution Non-Commercial License (http://creativecommons.org/licenses/by-nc/4.0/) which permits unrestricted non-commercial use, distribution, and reproduction in any medium, provided the original work is properly cited. 
larskeletal system and then an impact amplitude cumulated can increase dynamic-load to body (Voloshin and Loy, 1994). Ryu (2009) designed the time coordination system used with max generating-time mechanism to analyze cause of Knee flection, inward-rotation of tibia, abduction of foot in functions of lower leg and reported that higher heel showed proper time-coordination mechanism due to low max generating-time mechanism than that of lower heel.

Gerber et al. (2012) regarded lateral $\left(\mathrm{M}_{\mathrm{x}}\right)$, anterior-posterior $\left(\mathrm{M}_{\mathrm{y}}\right)$ rotation of GRF components as oscillation, and then various injuries can be generated during movement of foot segment, which can damage the function of center of pressure (COP). That is, higher heel height, the more function of cognitive sensory of vertical height at touch-down of next 1 step can be deteriorated (Hyun and Ryew, 2014c).

Overloaded COP distribution of midpost foot due to structural shape for part of fore part of shoe (Corrigan et al., 1993; Mandato and Nester, 1999; Morag and Cavanagh, 1999) could cause discomfort and plantar fasciitis and suggested possibility generating potential injuries as falling and sprain.

Like the former, In spite of problems of wearing of high heel, young female continuously prefer to wear due to not only more align closely to vertical direction of center of gravity of body but also provide longer length of lower leg viewing from frontal plane. Therefore considering the above, this study necessary to analyze the quantitative difference of transfer time between max peak amplitude for variable; peak vertical force (PVF), loading rate, free torque $\left(\mathrm{T}_{2}\right)$, required coefficient of friction $(\mathrm{RCOF})$ inducing sliding and falling related with COP displacement and provide basic materials for optimum height of heel shoes and dynamic stability during female's level walking.

\section{MATERIALS AND METHODS}

\section{Subject}

Subjects participated were composed of adult female subjects ( $\mathrm{n}=13$; mean age, $24.15 \pm 2.54$ years; mean height, $166.41 \pm 2.28$ $\mathrm{cm}$; mean body weight, $58.75 \pm 8.36 \mathrm{~kg}$ ) of 20 s with height of high heel $(0 \mathrm{~cm}, 9 \mathrm{~cm}$, respectively) and had habit of nonwearing over heel height of $3 \mathrm{~cm}$.

\section{Experimental procedure}

Height of $9 \mathrm{~cm}$ (shoe) and $0 \mathrm{~cm}$ (bare foot) were selected to analyze kinetic variables according to wearing of high heel shoe during level walking. All subjects were prohibited from wearing

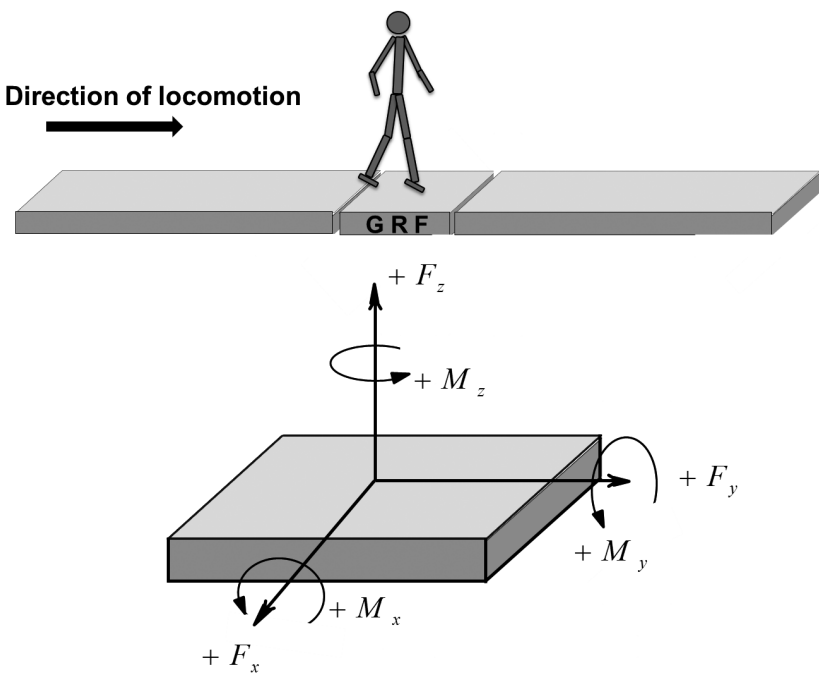

Fig. 1. Coordinates of the ground reaction force (GRF) measurement system ( $M x, M y$, and $\mathrm{Mz}$, moment about the vertical axis).

of socks to prevent errors data and coefficient of frictional force. Force plate (AMTI-OR9-7, AMTI, Watertown, MA, USA) was aligned with walking pathway after fixation and setting on the same level. When each subject was practiced repeatedly with high heel $(9 \mathrm{~cm})$ to keep eye's aiming of $45^{\circ}$ forwardly during walking, experiment data was collected for $10 \mathrm{sec}$. Each experiment was performed walking of 2 times on the force plate with sampling ratio of 1,000 Hz. Coordinate setting-up of force direction of force plate and experiment set-up was the same with (Fig. 1).

\section{Analysis and process of data}

PVF was normalized by subject's body weight and loading rate of impact was calculated with normalized PVF (Munro et al., 1987). That is, loading rate was calculated by vertical reaction force over $50 \mathrm{~N}$ minus $1 \mathrm{PVF} /$ time applied after touch-down on force plate right foot during walking.

$$
\text { Loading rate }=\frac{1 \text { PVF-F } 50^{+}}{\Delta t}
$$

RCOF was defined as value of medial-lateral GRF (ML GRF) and anterior-posterior GRF (AP GRF) divided by PVF, RCOF in ML direction and RCOF in AP direction was in the same line with (Asaka et al., 2002; Burnfield and Powers, 2007; Cooper et al., 2008).

$$
\mathrm{RCOF}=\frac{\sqrt{(\mathrm{ML} \mathrm{GRF})^{2}+(\mathrm{AP} \mathrm{GRF})^{2}}}{\mathrm{PVF}}
$$

First of all, $\mathrm{COP}_{\mathrm{x}}$ and $\mathrm{COP}_{\mathrm{y}}$ of $\mathrm{COP}$ for $\mathrm{T}_{z}$ was calculated and 
followed $\mathrm{COP}_{\mathrm{x}}=-\mathrm{M}_{\mathrm{y}}-\mathrm{F}_{\mathrm{x}} \times \mathrm{d}_{z} / \mathrm{F}_{\mathrm{z}}$ for COP location in $\mathrm{ML}, \mathrm{COP}_{\mathrm{y}}=$ $-\mathrm{M}_{\mathrm{x}}-\mathrm{F}_{\mathrm{y}} \times \mathrm{d}_{z} / \mathrm{F}_{z}$ for COP location in AP. Then, after fixing (reference point) the location of COP generated at angle of initial touchdown, displacement of location during supporting phase was calculated with absolute value.

$$
\mathrm{T}_{\mathrm{z}}=\mathrm{M}_{\mathrm{z}}+\left(\mathrm{F}_{\mathrm{x}} \times \mathrm{COP}_{\mathrm{y}}\right)-\left(\mathrm{F}_{\mathrm{y}} \times \mathrm{COP}_{\mathrm{x}}\right)
$$

$\mathrm{d}_{\mathrm{z}}$ : vertically downward location $(\mathrm{Z}=0)$ from origin point of force plate

First, mean \pm standard deviation for all variance calculated with PASW Statistics ver. 18.0 (SPSS Inc., Chicago, IL, USA), second, paired $t$-test was processed according to heel height $(0 \mathrm{~cm}$ [bare foot], $9 \mathrm{~cm}$ [shoes]) and third, transfer time for GRF was interpreted with 2-way analysis of variance of parameters of GRF $\times$ heel height. Post hoc test (Duncan) was treated in case of showing significant difference at $P<0.05$.

\section{RESULTS}

\section{Change of transfer time}

Analysis variables were as with the transfer time between GRF parameters, 1 PVF, 2 PVF, RCOFmax, elapsed time during supporting phase respectively (Table 1).

Transfer time showed significant difference with the more delay in $9 \mathrm{~cm}$ than that of 3 -cm heel height $(F=12.320, P<0.001)$ and also transfer time between parameters in GRF showed significant difference. Result of post hoc test, appearance of RCOFmax showed significant with the shortest of all parameters $(F=891.134$, $P<0.001)$.

\section{Change of GRF parameters according to heel height}

Parameters from GRF during supporting phase of gait were as with the 1 PVF, 2 PVF, and average value of parameters (Table 2). PVF showed significant difference with the more in $9 \mathrm{~cm}$ than

Table 1. Variance analysis on occurrence time during stance phase between $0 \mathrm{~cm}$ bare foot and $9 \mathrm{~cm}$ (unit: sec)

\begin{tabular}{|c|c|c|c|c|c|c|c|}
\hline \multirow{2}{*}{ Section } & \multicolumn{2}{|c|}{ Heel height } & \multirow{2}{*}{ Total average } & \multirow{2}{*}{ Source } & \multirow{2}{*}{$F$} & \multirow{2}{*}{$P$-value } & \multirow{2}{*}{ Posthoc } \\
\hline & $0 \mathrm{~cm}$ (bare foot) & $9 \mathrm{~cm}$ (shoe) & & & & & \\
\hline 1st PVF & $0.155 \pm 0.04$ & $0.161 \pm 0.03$ & $0.158 \pm 0.04$ & $\mathrm{H}$ & 12.320 & $<0.001^{* * *}$ & $9 \mathrm{~cm}>0 \mathrm{~cm}$ \\
\hline 2nd PVF & $0.496 \pm 0.03$ & $0.546 \pm 0.05$ & $0.521 \pm 0.05$ & & & & \\
\hline Stance phase & $0.650 \pm 0.06$ & $0.693 \pm 0.07$ & $0.061 \pm 0.07$ & T & 891.134 & $<0.001^{* * *}$ & $\begin{array}{c}\mathrm{RCOF}>\mathrm{Fz} 1>\mathrm{Fz} 2> \\
\text { stance time }\end{array}$ \\
\hline RCOFmax & $0.042 \pm 0.01$ & $0.079 \pm 0.01$ & $0.671 \pm 0.02$ & & & & \\
\hline Total average & $0.336 \pm 0.25$ & $0.370 \pm 0.26$ & $0.353 \pm 0.25$ & $\mathrm{H} \times \mathrm{T}$ & 0.974 & 0.408 & - \\
\hline
\end{tabular}

Values are presented as mean \pm standard deviation.

PVF, peak vertical force; RCOFmax, required coefficient of friction maximum; $H$, heel heights of the main effect; $T$, time of the main effect; $H \times T$, interaction $0 \mathrm{~cm}$ and $9 \mathrm{~cm}$ in gait. ${ }^{* * *} P<0.001$.

Table 2. Ground reaction force parameters during stance phase between $0 \mathrm{~cm}$ and $9 \mathrm{~cm}$

\begin{tabular}{|c|c|c|c|c|c|}
\hline \multirow{2}{*}{ Section } & \multirow{2}{*}{ Parameter } & \multicolumn{2}{|c|}{ Heel height } & \multirow{2}{*}{$t$} & \multirow{2}{*}{$P$-value } \\
\hline & & $0 \mathrm{~cm}$ (bare foot) & $9 \mathrm{~cm}$ (shoe) & & \\
\hline RCOFmax & RCOF & $0.25 \pm 0.06$ & $0.29 \pm 0.06$ & 1.611 & 0.120 \\
\hline \multirow[t]{4}{*}{$1 \mathrm{PVF}$} & $\mathrm{PVF}(\mathrm{N} / \mathrm{BW})$ & $1.05 \pm 0.08$ & $1.21 \pm 0.13$ & 3.847 & $<0.001^{* * *}$ \\
\hline & Loading rate (N/BW/sec) & $7.42 \pm 2.61$ & $8.38 \pm 4.31$ & 0.689 & 0.497 \\
\hline & $\mathrm{RCOF}$ & $0.13 \pm 0.05$ & $0.16 \pm 0.04$ & 1.993 & 0.058 \\
\hline & Free Torque (N-m) & $-0.38 \pm 1.22$ & $-0.78 \pm 1.21$ & 0.832 & 0.414 \\
\hline \multirow[t]{3}{*}{$2 \mathrm{PVF}$} & PVF (N/BW) & $1.10 \pm 0.07$ & $1.12 \pm 0.10$ & 0.556 & 0.583 \\
\hline & $\mathrm{RCOF}$ & $0.14 \pm 0.03$ & $0.17 \pm 0.03$ & 2.132 & $0.043^{*}$ \\
\hline & Free Torque (N-m) & $2.14 \pm 1.32$ & $1.36 \pm 0.79$ & 1.814 & 0.082 \\
\hline \multirow[t]{3}{*}{ Average } & RCOF & $0.14 \pm 0.02$ & $0.13 \pm 0.02$ & 0.668 & 0.510 \\
\hline & Medial-lateral COP ABS (cm) & $1.91 \pm 1.32$ & $1.29 \pm 0.98$ & 1.364 & 0.185 \\
\hline & Anterior-posterior COP ABS (cm) & $7.97 \pm 3.18$ & $6.65 \pm 3.80$ & 0.959 & 0.347 \\
\hline
\end{tabular}

Values are presented as mean \pm standard deviation.

RCOF, required coefficient of friction; RCOFmax, RCOF maximum; PVF, peak vertical force; BW, body weight; COP, center of pressure; ABS, absolute value.

${ }^{*} P<0.05$. ${ }^{* *} P<0.001$. 
that of $0 \mathrm{~cm}$ of heel height $(P<0.001)$, but did not show in loading rate, RCOF, $\mathrm{T}_{\mathrm{z}}$ at 1 PVF. PVF and torque did not show but RCOF showed significant difference with the more value in $9 \mathrm{~cm}$ than that of $0 \mathrm{~cm}$ during supporting phase of gait $(P<0.05)$.

$\mathrm{T}_{2}$ showed significant difference with the more rotational force at $0 \mathrm{~cm}$ than that of $9 \mathrm{~cm}$, but did not show in parameters of RCOF, COPx, COPy, respectively.

\section{DISCUSSION}

The duration which can be minimize stresses acting on foot and its muscularskeletal system is supporting phase among all phases of gait cycle (Gefen et al., 2001). But in case of wearing high heel shoe, excessive impact on ankle due to cognition error of exact touch-down distance to ground at heel touch-down by hyper-plantar flexion of ankle joint can be generated (Hyun and Ryew, 2014c).

PVF and load rate in this study showed the greater in $9 \mathrm{~cm}$ than that $0 \mathrm{~cm}$, and particularly total time elapsed showed $0.650 \mathrm{sec}$ in $0 \mathrm{~cm}$ and $0.693 \mathrm{sec}$ in $9 \mathrm{~cm}$ respectively, but, transfer time for 1 PVF showed similar result. Therefore it was considered that gait wore high heel of $9 \mathrm{~cm}$ generated the greater load rate. While $T_{z}$ at 1 PVF showed $-0.38 \mathrm{~N}-\mathrm{m}$ of $0 \mathrm{~cm}$, and $-0.78 \mathrm{~N}-\mathrm{m}$ of $9 \mathrm{~cm}$, showed $2.14 \mathrm{~N}-\mathrm{m}$ of $0 \mathrm{~cm}$ and $1.36 \mathrm{~N}-\mathrm{m}$ of $9 \mathrm{~cm}$ at 2 PVF respectively.

Inward rotation of tibia to longitudinal axis can be generated when ankle joint was pronated to the subtalar joint during locomotion (Ryu, 2010). But because pronation and inward rotation of tibia according to increase of heel height can be generated concurrently, the greater movement of high heel shoe in lower leg showed than that of not (Gajdosik et al., 1999). On the basis of the above view, it was considered to compensate on the instability of locomotion when inward and outward rotation of tibia resulted from inversion and eversion can cause an interaction effect influencing on knee joint due to hyper-plantar flexion of ankle joint during gait with high heel shoe (Lundberg et al., 1989).

COP variable of this study analyzed only during supporting phase, and calculated absolute mean value of change of displacement from touch down to take off of COP after propulsive phase. The result did not show significant difference according to heel height, but showed less change of displacement on $9 \mathrm{~cm}$ than that of $0 \mathrm{~cm}$ in both COPx and COPy. Proper change in displacement of COP could not only reduce and control the velocity of COP but also induced efficient gait during propulsive phase (Hyun and Ryew, 2014b), but relative minute range of displacement at high heel of $9 \mathrm{~cm}$ suggested a failure of function on the posture control during gait.

That is, it may say that muscle fatigue could be cumulated as with increase of instability by the loss of control function in locomotion velocity (Ebbeling et al., 1994; Gefen et al., 2002; Valentini et al., 2009).

Calculation of RCOF was divided with vertical components of ML GRF and AP GRF, and RCOF showed greater value on high heel of $9 \mathrm{~cm}$ than that of $0 \mathrm{~cm}$ during both $1 \mathrm{PVF}$ and $2 \mathrm{PVF}$ due to increase of ML GRF and AP GRF in case of $9 \mathrm{~cm}$. The above result can be explained with an interaction of material and environmental factor, friction coefficient of floor and sensory of neuromuscular function which may cause injuries of sliding and falling etc. (Hanson et al., 1999; Redfern and Dipasquale, 1997; Strandberg and Lanshammar, 1981; Tang and Woollacott, 1998).

Gait by high heel shoe divided as environmental factor can be regarded as important factor of frictional coefficient for structural problem of shoes, and also ratio of falling injury can be high due to more narrow area of touch down relative to gait of touch down by the sole of a foot to ground by arch type of midsole in case of bare foot.

Also transfer time showed faster at RCOFmax than in case of 1 PVF, and showed the shorter time in the transfer time than that of absorption time of impact to the body. Therefore gait of high heel shoe could not control efficiently the GRF and then increased the possibility of injuries of sliding and falling, and muscle fatigue due to decrease of the control ability of frictional coefficient.

When considering the above, It is important to select proper height of heel in female walking, but rather more to consider design of shoes of material and shape in course of manufacturing.

\section{CONFLICT OF INTEREST}

No potential conflict of interest relevant to this article was reported.

\section{REFERENCES}

Asaka T, Saito H, Yoshida N, Urakami D, Kamada K, Fukushima J. Relationship between the required coefficient of friction and gait initiation in young adults on a low friction floor. J Phys Ther Sci 2002;14:33-39.

Burnfield JM, Powers CM. The role of center of mass kinematics in predicting peak utilized coefficient of friction during walking. J Forensic Sci 2007;52:1328-1333.

Cooper RC, Prebeau-Menezes LM, Butcher MT, Bertram JE. Step length 
and required friction in walking. Gait Posture 2008;27:547-551.

Corrigan JP, Moore DP, Stephens MM. Effect of heel height on forefoot loading. Foot Ankle 1993;14:148-152.

Csapo R, Maganaris CN, Seynnes OR, Narici MV. On muscle, tendon and high heels. J Exp Biol 2010;213(Pt 15):2582-2588.

Ebbeling CJ, Hamill J, Crussemeyer JA. Lower extremity mechanics and energy cost of walking in high-heeled shoes. J Orthop Sports Phys Ther 1994;19:190-196.

Gajdosik RL, Vander Linden DW, Williams AK. Influence of age on length and passive elastic stiffness characteristics of the calf muscle-tendon unit of women. Phys Ther 1999;79:827-838.

Gefen A, Megido-Ravid M, Itzchak Y. In vivo biomechanical behavior of the human heel pad during the stance phase of gait. J Biomech 2001; 34:1661-1665.

Gefen A, Megido-Ravid M, Itzchak Y, Arcan M. Analysis of muscular fatigue and foot stability during high-heeled gait. Gait Posture 2002; 15:56-63.

Gerber SB, Costa RV, Grecco LA, Pasini H, Marconi NF, Oliveira CS. Interference of high-heeled shoes in static balance among young women. Hum Mov Sci 2012;31:1247-1252.

Hanson JP, Redfern MS, Mazumdar M. Predicting slips and falls considering required and available friction. Ergonomics 1999;42:1619-1633.

Hyun SH, Ryew CC. Analysis of the gait characteristics and interaction among bilateral lower extremity joints according to shoe's heel heights in young women. Korean J Sport Biomech 2014a;24:445-453.

Hyun SH, Ryew CC. Comparison analysis of ground reaction force patterns according to the stairs heights and bag weights during downward stairs in women. Kinesiology 2014b;16:41-52.

Hyun SH, Ryew CC. Investigation of the ground reaction force parameters according to the shoe's heel heights and landing distance during downward stairs on bus. Korean J Sport Biomech 2014c;24:151-160.

Leardini A, Benedetti MG, Catani F, Simoncini L, Giannini S. An anatomically based protocol for the description of foot segment kinematics during gait. Clin Biomech (Bristol, Avon) 1999;14:528-536.

Lundberg A, Goldie I, Kalin B, Selvik G. Kinematics of the ankle/foot complex: plantarflexion and dorsiflexion. Foot Ankle 1989;9:194-200.

Mandato MG, Nester E. The effects of increasing heel height on forefoot peak pressure. J Am Podiatr Med Assoc 1999;89:75-80.

Morag E, Cavanagh PR. Structural and functional predictors of regional peak pressures under the foot during walking. J Biomech 1999;32:359370.

Munro CF, Miller DI, Fuglevand AJ. Ground reaction forces in running: a reexamination. J Biomech 1987;20:147-155.

Nigg B, Hintzen S, Ferber R. Effect of an unstable shoe construction on lower extremity gait characteristics. Clin Biomech (Bristol, Avon) 2006;21:82-88.

Redfern MS, DiPasquale J. Biomechanics of descending ramps. Gait Posture 1997;6:119-125.

Rodgers MM. Dynamic foot biomechanics. J Orthop Sports Phys Ther 1995;21:306-316.

Ryu JS. Effects of high-heeled shoe with different height on the balance during standing and walking. Korean J Sport Biomech 2010;20:479486.

Ryu JS. The temporal coordination of the lower extremity by increasing high-heel height during walking. Korean J Sport Biomech 2009;19:593601.

Stefanyshyn DJ, Nigg BM, Fisher V, O Flynn B, Liu W. The influence of high heeled shoes on kinematics, kinetics, and muscle EMG of normal female gait. J Appl Biomech 2000;16:309-319.

Strandberg L, Lanshammar $\mathrm{H}$. The dynamics of slipping accidents. J Occup Accid 1981;3:153-162.

Tang PF, Woollacott MH. Inefficient postural responses to unexpected slips during walking in older adults. J Gerontol A Biol Sci Med Sci 1998;53:M471-480.

Valentini R, Martinelli B, Mezzarobba S, De Michiel A, Toffano M. Optokinetic analysis of gait cycle during walking with $1 \mathrm{~cm}$ - and $2 \mathrm{~cm}$-high heel lifts. Foot (Edinb) 2009;19:44-49.

Voloshin AS, Loy DJ. Biomechanical evaluation and management of the shock waves resulting from the high-heel gait: I-temporal domain study. Gait Posture 1994;2:117-122. 